\title{
Femoroacetabular impingement surgery allows $74 \%$ of athletes to return to the same competitive level of sports participation but their level of performance remains unreported: a systematic review with meta-analysis
}

\author{
Michael P Reiman, ${ }^{1}$ Scott Peters, ${ }^{2}$ Jonathan Sylvain, ${ }^{3}$ Seth Hagymasi, ${ }^{3}$ \\ Richard C Mather, ${ }^{1}$ Adam P Goode ${ }^{1}$
}

- Additional material is published online only. To view please visit the journal online (http://dx.doi.org/10.1136/ bjsports-2017-098696).

1 Department of Orthopedic Surgery, Duke University Medical Center, Durham, North Carolina, USA

${ }^{2}$ Toronto Blue Jays Baseball Club, Toronto, Ontario, Canada ${ }^{3}$ University of Connecticut Health Center, Farmington, Connecticut, USA

\section{Correspondence to} Dr Michael P Reiman, Department of Orthopedic Surgery, Duke University Medical Center, Durham, NA 27710, USA;

reiman.michael@gmail.com

Accepted 20 February 2018 Published Online First 26 March 2018
Check for updates

To cite: Reiman MP, Peters S, Sylvain J, et al. Br I Sports Med 2018:52:972-981.

\section{ABSTRACT}

Background Femoroacetabular impingement (FAI) syndrome is one source of hip pain that can limit sport participation among athletes.

Objective To summarise the return to sport (RTS) rate for athletes after surgery for FAI syndrome.

Methods A computer-assisted search of MEDLINE, the Cumulative Index to Nursing and Allied Health Literature (CINAHL) and EMBASE databases was performed using keywords related to RTS and RTS at preinjury level ( RTS $_{\text {PRE }}$ ) of competition for FAl syndrome. The risk of bias in the included studies was assessed using the Methodological Index for Non-Randomized Studies scale.

Results 35 studies (1634 athletes/1828 hips) qualified for analysis. Based on evidence of limited to moderate strength (level 3b to 4 studies), athletes return to sport at preinjury level post surgery for FAl syndrome at a rate of only $74 \%(67 \%-81 \%)$. Only $37 \%$ of studies reported RTS $_{\text {PRE }}$. The mean time from surgery to RTS was $7.0 \pm 2.6$ months. The mean follow-up postsurgery was $28.1 \pm 15.5$ months. Professional athletes returned to sport $(p=0.0002)$ (although not the preinjury sport level; $p=0.63$ ) at a higher rate than collegiate athletes. Only $14 \%$ of studies reported on athletic presurgery and postsurgery athletic performance, which means it is impossible to comment on whether athletes return to their previous level of performance or not. No studies reported on the specific criteria used to permit players to return to sport. $20 \%$ of studies reported on career longevity, $51 \%$ reported surgical complications and $77 \%$ reported on surgical failures.

Conclusion There was limited to moderate evidence that one in four athletes did not return to their previous level of sport participation after surgery for FAl syndrome. Only $37 \%$ of the included studies clearly distinguished RTS from RTS $_{\text {PRE. }}$ Poor outcome reporting on athletic performance postsurgery makes it difficult to determine to what level of performance these athletes actually perform. Thus, if a player asks a surgeon 'Will I get back to my previous level of performance?' there are presently little to no published data from which to base an answer.

PROSPERO registration number CRD42017072762.

\section{INTRODUCTION}

The 2016 Warwick Agreement on femoroacetabular impingement (FAI) syndrome states that to reach a diagnosis of FAI syndrome, patients should have appropriate symptoms, positive clinical signs and imaging findings. ${ }^{1}$ Patients with FAI syndrome and intra-articular pathology, including acetabular labral tears and cartilage pathology, have reported groin pain, reduced quality of life and functional limitations in most aspects of daily living, including

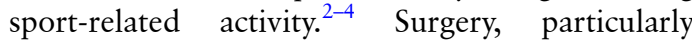
arthroscopic hip surgery (including bony debridement \pm labral reconstruction), has been increasingly offered to these patients in an attempt to control pain and improve function. ${ }^{5}$ However, whether such surgery permits successful return to sport (RTS) is unclear. 'Successful' RTS has at least three elements: (1) playing the sport again (at any level), (2) playing the sport again at the previous level of competition (ie, National Collegiate Athletic Association (NCAA) or professional league) and (3) performing at a previous level using objective sports performance criteria relevant to the sport (ie, world ranking in tennis). ${ }^{6}$ "Doc, will this surgery allow me to return to sport?" is a question that every athlete asks when considering surgery as a treatment option.

Although previous reviews reported RTS after hip surgery for athletes with FAI syndrome, ${ }^{34}$ these reviews did not differentiate RTS (at any level) versus return to preinjury competition level of sport $\left(\mathrm{RTS}_{\mathrm{PRE}}\right)$. Those reviews did not report athletes' level of performance if they returned to sport at the preinjury competition level. Previous reviews also failed to report the level of evidence of their conclusions relating to RTS after hip surgery for FAI.

Therefore, the aims of this systematic review were to report (1) the broad RTS rate among athletes after surgery for FAI syndrome, (2) the rate of return to play at the preinjury (or higher) level of competition among athletes after surgery for FAI syndrome $\left(\mathrm{RTS}_{\mathrm{PRE}}\right)$ and (3) athletes' postsurgery athletic performance in those cases where they returned to their previous level of competition.

\section{METHODS}

\section{Protocol and registration}

We followed the Preferred Reporting Items for Systematic Reviews and Meta-Analyses guidelines during the search and reporting phase of this review.

The review was registered on 3 August 2017, with the International Prospective Register of Systematic 
Reviews (Prospero \#CRD42017072762). The review protocol was registered after the pilot literature search and before the updated literature search and data extraction.

\section{Identification and selection of the literature}

We searched the MEDLINE, the Cumulative Index to Nursing and Allied Health Literature (CINAHL) and EMBASE databases from inception until 31 July 2017. Unpublished literature was also searched via Google Scholar. The search strategy was developed in collaboration with a biomedical librarian and used controlled vocabulary and keywords related to RTS, relative to FAI syndrome and labral tear. The search was limited to humans and English-language publications. The full search strategy for MEDLINE is listed in online supplementary appendix 1. As computerised search results for diagnostic accuracy data frequently omit relevant studies, ${ }^{7}$ systematic reviews and included studies were also screened to detect eligible studies that were not identified by the electronic search. To be included in the systematic review, the studies had to satisfy the following criteria:

- Study design: The study is a prospective or retrospective cohort and/or case series with a population greater than 10 athletes.

- Patients: Athletes (as defined by each respective study) are in any age group or athletic competition level (professional, college, high school or middle school, amateur/recreational) with a diagnosis of FAI syndrome. The FAI syndrome diagnosis was per report from each respective study. At least $80 \%$ of participants in a study were treated primarily for FAI. Patients with hip dysplasia, slipped capital femoral epiphysis or Legg-Calve-Perthes disease, patients with previous hip arthroscopic or open surgery (revision surgery), and patients undergoing periacetabular osteotomy were excluded.

- Intervention: Patients had to be treated with hip preservation surgery (eg, open, arthroscopy, combination procedures).

- Comparator: Not applicable.

- Outcomes: Patient report of RTS (any level) and RTS $\mathrm{PRE}_{\text {(RTS }}$ at the preinjury level of competition). Secondary outcomes included patient-reported outcome measures (PROMs), surgical complication and failure rates, time to RTS and $\mathrm{RTS}_{\mathrm{PRE}}$, athlete and sport types included, surgical procedure(s), postsurgical athletic performance, career longevity, or RTS criteria.

We also excluded systematic reviews related to surgery for FAI syndrome. Studies that did not present RTS data were excluded.

To identify relevant studies, two reviewers independently screened titles and abstracts of all identified citations. Fulltext studies were retrieved and screened independently by the two reviewers if the abstract provided insufficient information to establish eligibility, or if the study passed the first eligibility screening. Disagreements were resolved by consensus.

\section{Risk of bias assessment}

Two reviewers independently assessed the risk of bias for each included study using the Methodological Index for Non-Randomized Studies (MINORS) scale. ${ }^{8}$ This tool was specifically developed and validated to evaluate the quality of non-randomised surgical studies. It includes 12 items; the last 4 are specific for comparative studies. Each item included in the MINORS scale is scored as follows: 0 indicates that the content has not been reported; 1 that the content has been reported inadequately; and 2 that the content has been sufficiently reported. The highest possible score is 16 for a non-comparative study and
24 for a comparative study. The results of the risk of bias assessment were used to give an overview of the potential sources of bias in included studies. Studies were not excluded from the analysis based on the assessment of risk of bias. Disagreements were resolved via consensus. The quality of the studies was rated based on the MINORS criteria as previously described ${ }^{910}$ :

- high quality: studies that met $>75 \%$ of the criteria

- moderate quality: studies that met between $50 \%$ and $74 \%$ of the criteria

- low quality: studies that met between $25 \%$ and $49 \%$ of the criteria

- very low quality: studies that met $<25 \%$ of the score criteria. Subgroup analyses, based on surgical treatment comparison, were performed when available (arthroscopy vs open vs mini-open surgical procedure), and athletic participation level (professional vs collegiate vs adolescent athlete). We judged the level of evidence of each study. ${ }^{11}$

Definitions for levels of evidence for pooled results on RTS and RTS ${ }_{\text {PRE }}$ were guided by previous recommendations ${ }^{1213}$ :

- strong evidence: pooled results derived from three or more studies, including a minimum of two high-quality studies that were statistically homogeneous $(P>0.05)$; may be associated with a statistically significant or non-significant pooled result

- moderate evidence: statistically significant pooled results derived from multiple studies, including at least one highquality study that was statistically heterogeneous $(\mathrm{P}<0.05)$; or from multiple low-quality or moderate-quality studies that were statistically homogeneous $(\mathrm{P}>0.05)$

- limited evidence: pooled results from multiple low-quality or moderate-quality studies that were statistically heterogeneous $(\mathrm{P}<0.05)$; or from one high-quality study

- very limited evidence: results from one low-quality study

- conflicting evidence: pooled results insignificant and derived from multiple studies regardless of quality, of which some show statistical significance individually, which are statistically heterogeneous $(\mathrm{p}<0.05$, ie, inconsistent $)$.

\section{Data extraction}

Data were extracted independently by one reviewer and verified by a second independent reviewer. We extracted the characteristics of the study participants (number of athletes, sex, age, competition level, sport activity), the description of surgery for FAI syndrome (surgical technique, concomitant surgical procedures) and outcomes (RTS, RTS $\mathrm{PRE}_{\mathrm{PE}}$, time to RTS, sports performance, PROMs, time of follow-up, athlete retention, career longevity).

\section{Definition of RTS and RTS}

We operationally defined RTS and RTS at preinjury $\left(\mathrm{RTS}_{\mathrm{PRE}}\right)$ as the following:

- RTS, return to sport: any athlete returning to any level of competitive sport

- $\operatorname{RTS}_{\mathrm{PRE}}$, return to sport at preinjury level: athlete returned to play at or above the preinjury level.

Studies must have differentiated between the athletes returning to sport (RTS) and those returning to the preinjury level of competition ( $\mathrm{RTS}_{\mathrm{PRE}}$ ) for data to be collected and combined in meta-analyses. RTS data from studies that did not explicitly state the number of athletes returning to preinjury level of sports competition were combined via meta-analysis for RTS only.

Studies only reporting RTS $_{\text {PRE }}$ data had RTS and RTS PRE reported as the same rate. 


\section{Sports categories and activity levels}

The sports categories ${ }^{14}{ }^{15}$ and activity levels ${ }^{16}$ represented in the included studies were determined as per previously published standards. There are six distinct sports categories based on the mechanical loads placed on the hip by the sporting activity. Sports that have previously been described include cutting, flexibility, contact, impingement, asymmetric/overload and endurance sports categories relative to athletes with FAI syndrome. ${ }^{14} 15$ The Hip Sports Activity Scale describes an athlete's competition level from no recreational or competitive sports (level 0 ) through competitive sports (elite level) (level 8). ${ }^{16}$

\section{Data synthesis and analysis}

Percentage agreement and Cohen $\mathrm{K}$ statistics were calculated to provide absolute agreement between raters for study inclusion. Descriptive statistics were calculated for all variables that were not included in meta-analysis (eg, performance, RTS times, complications, failures) (Microsoft Excel, Microsoft Corporation, Santa Rosa, California).

We determined which studies to include for meta-analysis by judging both clinical and statistical heterogeneity, and considering the risk of bias assessment. Clinical judgement criteria involved assessment of similarity of populations and assessment context (eg, athlete level, surgical procedure a priori). ${ }^{17}$ In addition, after approval using clinical judgement, studies were statistically pooled when $\geq 2$ studies examined either the same athlete level or surgical procedures and RTS variable (either RTS or RTS PRE$_{\text {) }}$.

We calculated the pooled prevalence rate and $95 \% \mathrm{CI}$ for outcome after various types of surgery and for athlete level (eg, professional, collegiate, adolescent, recreational). These were separated and further analysed for RTS and RTS $\mathrm{PRE}$. DerSimonian and Laird random-effect models ${ }^{18}$ with inverse variance weighting were used for all analyses. A Freeman-Tukey double arcsine transforma$\operatorname{tion}^{19}$ was used to stabilise the variances prior to data pooling.

To determine if differences across surgical treatment groups existed, a test of homogeneity of rates was used with a $p<0.05$ indicating significant differences between the pooled estimates of groups. Heterogeneity was assessed with Cochran's Q and $\mathrm{I}^{2}$. High heterogeneity was indicated by a $Q \mathrm{p}$ value $<0.10$ and $\mathrm{I}^{2}>50 \% .^{20}$ In one instance $\left(\mathrm{RTS}_{\mathrm{PRE}}\right.$ for open surgical procedure), the model was unable to determine study heterogeneity due to a small number of included studies. We did not attempt to conduct simple sensitivity analyses by removal of studies and comparison with overall pooled estimates due to the limited number of categories with a meaningful number of studies. Instead we focused on the comparison between the individual category pooled estimates in relation to the overall pooled estimates and changes in heterogeneity. $\mathrm{X}^{2}$ analysis was used to perform within-group comparison (comparator) differences in RTS for all studies.

\section{RESULTS}

Three hundred and thirty-two titles were identified through database and reference searches. Fifty-one full texts were assessed for eligibility for inclusion, and we included 35 studies (1634 participants) in this systematic review (figure 1). The reasons for study exclusion from full-text review as well as potential sources of study support are reported in online supplementary appendix II.

\section{Quality assessment of studies}

Ten studies ${ }^{21-30}$ ( $29 \%$ of all studies) were prospective, while the remaining 25 studies $^{29-53}(71 \%)$ were retrospective (table 1). Four

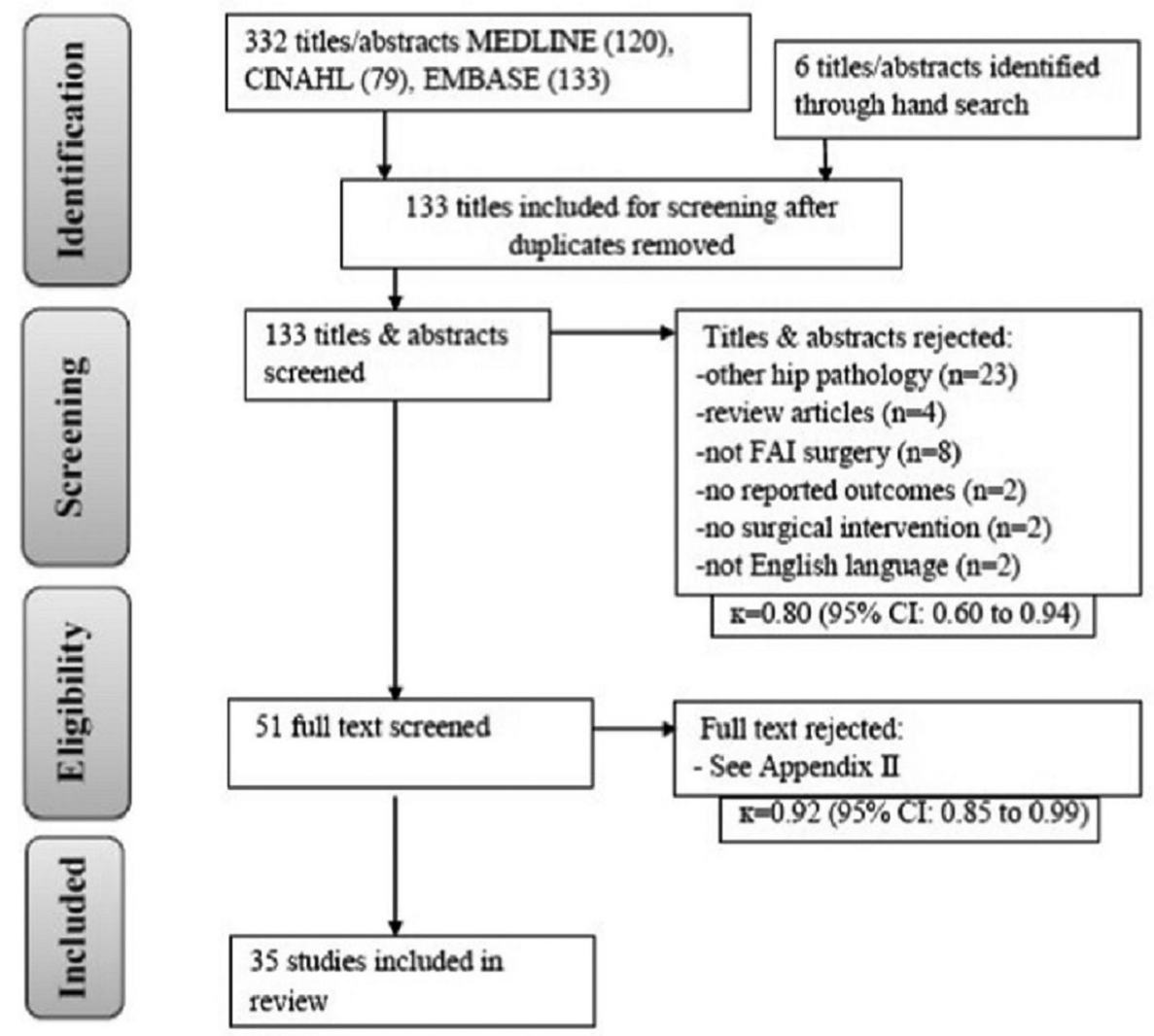

Figure 1 Preferred Reporting Items for Systematic Reviews and Meta-Analyses flow diagram. FAl, femoroacetabular impingement. 


\begin{tabular}{|c|c|c|c|}
\hline Study & Athletes (n, sex, mean age) & Athletes' level & Sport \\
\hline $\begin{array}{l}\text { Amenabar and O'Donnell } \\
(2013)^{33}\end{array}$ & 26 , male, 21.8 years & Professional & $\begin{array}{l}\text { Australian } \\
\text { football }\end{array}$ \\
\hline Barastegui et al $(2017)^{34}$ & 21 , male, 26.5 years & Professional & Football \\
\hline Boykin et al $(2013)^{35}$ & 21 , male, 28 years & Professional & Multiple \\
\hline Brunner et al (2009) $)^{30}$ & $45 ; 33$ male, 41 years & Recreational & Multiple \\
\hline Byrd and Jones (2011) $)^{21}$ & $200 ; 148$ male, 28.6 years & $\begin{array}{l}\text { Professional } \\
\text { Collegiate } \\
\text { High school } \\
\text { Recreational }\end{array}$ & Multiple \\
\hline Byrd et al (2016) $)^{22}$ & 104; 47 male, 16 years & High school & Multiple \\
\hline Cohen et al $(2012)^{23}$ & 44, not reported, not reported & $\begin{array}{l}\text { Amateur to } \\
\text { professional }\end{array}$ & Multiple \\
\hline Cvetanovich et al (2016) $)^{36}$ & $37 ; 11$ male, 17 years & $\begin{array}{l}\text { Collegiate } \\
\text { High school }\end{array}$ & Not reported \\
\hline Degen et al $(2016)^{24}$ & 50, male, 22.4 years & $\begin{array}{l}\text { Professional } \\
\text { Collegiate } \\
\text { High school or } \\
\text { club team }\end{array}$ & Baseball \\
\hline Hammoud et al (2012) $)^{37}$ & 38 , male, 31 years & Professional & Multiple \\
\hline Klingenstein et al (2012) ${ }^{38}$ & $34 ; 29$ male, 21.4 years & $\begin{array}{l}\text { Professional } \\
\text { Collegiate } \\
\text { High school }\end{array}$ & $\begin{array}{l}\text { Baseball } \\
\text { Lacrosse }\end{array}$ \\
\hline Levy et al $(2017)^{39}$ & $51 ; 22$ male, 26.3 years & $\begin{array}{l}\text { Collegiate } \\
\text { High school } \\
\text { Amateur }\end{array}$ & Running \\
\hline Malagelada et al (2015) & $15 ; 9$ male, 40.8 years & Recreational & Multiple \\
\hline Malviya et al $(2013)^{26}$ & $80 ; 50$ male, 35.7 years & $\begin{array}{l}\text { Professional } \\
\text { Recreational }\end{array}$ & Multiple \\
\hline McDonald et al (2014) $)^{32}$ & 17 , male, 31 years & Professional & Hockey \\
\hline Menge et al $(2016)^{40}$ & 60, male, 27 years & Professional & Hockey \\
\hline Naal et al $(2011)^{41}$ & 22 , male, 19.7 years & Professional & Multiple \\
\hline Naal et al $(2014)^{42}$ & 126; 91 male, 30 years & Not reported & Multiple \\
\hline Newman et al (2016) $)^{43}$ & 20 , male, 38 years & Professional & Golf \\
\hline Nho et al $(2011)^{44}$ & 33 , not reported, 22.8 years & $\begin{array}{l}\text { Professional } \\
\text { Collegiate } \\
\text { High school }\end{array}$ & Multiple \\
\hline Novais et al (2016) $)^{45}$ & $24 ; 12$ male, 15.5 years & High school & Multiple \\
\hline Perets et al (2017) $)^{46}$ & $41 ; 8$ male, 19.3 years & $\begin{array}{l}\text { Professional } \\
\text { Collegiate } \\
\text { High school }\end{array}$ & Multiple \\
\hline Philippon et al (2007) ${ }^{47}$ & $45 ; 42$ male, 31 years & Professional & Multiple \\
\hline Philippon et al (2008) & $16 ; 2$ male, 15 years & High school & Multiple \\
\hline Philippon et al (2010) & 28 , male, 27 years & Professional & Hockey \\
\hline Polesello et al $(2012)^{50}$ & 42, not reported, 36 years & Not reported & Not reported \\
\hline Polesello et al (2014) & 14 , not reported, 34.6 years & $\begin{array}{l}\text { Professional } \\
\text { Recreational }\end{array}$ & Not reported \\
\hline Ribas et al $(2007)^{51}$ & $32 ; 23$ male, 36.2 years & Not reported & Multiple \\
\hline Sansone et al $(2015)^{27}$ & $85 ; 68$ male, 25 years & Professional & Multiple \\
\hline Shibata et al $(2017)^{14}$ & $80 ; 42$ male, 21 years & $\begin{array}{l}\text { Professional } \\
\text { Olympic } \\
\text { Collegiate }\end{array}$ & Multiple \\
\hline $\begin{array}{l}\text { Singh and } O^{\prime} \text { Donnell } \\
(2010)^{52}\end{array}$ & 24 , male, 22 years & Professional & $\begin{array}{l}\text { Australian } \\
\text { football }\end{array}$ \\
\hline Tjong et al (2016) $)^{53}$ & 23; 8 male, 43.9 years & $\begin{array}{l}\text { Collegiate } \\
\text { Recreational }\end{array}$ & Swimming \\
\hline Tran et al (2013) & $32 ; 29$ male, 15.7 years & High school & $\begin{array}{l}\text { Australian } \\
\text { football }\end{array}$ \\
\hline Weber et al $(2016)^{31}$ & $66 ; 26$ male, 26.8 years & $\begin{array}{l}\text { Recreational } \\
\text { Amateur }\end{array}$ & Not reported \\
\hline Zingg et al $(2013)^{28}$ & $38 ; 29$ male, 28.3 years & Not reported & Not reported \\
\hline
\end{tabular}

studies ${ }^{14283132}$ (11\% of all studies) were level 3 b evidence, and 31 studies $^{21-272933-54}$ (89\%) were level 4 evidence. ${ }^{11}$ The methodological quality of scores ranged from $6^{24}$ to $16,{ }^{26}$ with a median of 9 (online supplementary appendix III). Twenty-seven studies (77\%) were of moderate quality ${ }^{1421-2325-32353840-4850515354}$ and
Table 2 Sports level (HSAS) and category of included studies

\begin{tabular}{|c|c|c|}
\hline Study & $\begin{array}{l}\text { Sport level } \\
\text { (HSAS) }^{1416}\end{array}$ & Sports category ${ }^{1415}$ \\
\hline $\begin{array}{l}\text { Amenabar and O'Donnell } \\
(2013)^{33}\end{array}$ & 8 & Contact \\
\hline Barastegui et al (2017) $)^{34}$ & 8 & Cutting \\
\hline Boykin et al $(2013)^{35}$ & 7,8 & $\begin{array}{l}\text { Cutting, impingement, contact, } \\
\text { asymmetric, flexibility }\end{array}$ \\
\hline Brunner et al $(2009)^{30}$ & $1-4$ & Cutting, impingement, endurance \\
\hline Byrd and Jones $(2011)^{21}$ & $1-8$ & $\begin{array}{l}\text { Cutting, impingement, contact, } \\
\text { asymmetric, flexibility, endurance }\end{array}$ \\
\hline Byrd et al $(2016)^{22}$ & $1-4$ & $\begin{array}{l}\text { Cutting, impingement, contact, } \\
\text { asymmetric, flexibility, endurance }\end{array}$ \\
\hline Cohen et al $(2012)^{23}$ & $1-4$ & $\begin{array}{l}\text { Cutting, impingement, contact, } \\
\text { asymmetric, flexibility, endurance }\end{array}$ \\
\hline Cvetanovich et al (2016) & Not reported & Not reported \\
\hline Degen et al $(2016)^{24}$ & $4,7,8$ & Asymmetric \\
\hline Hammoud et al (2012) & 6,8 & $\begin{array}{l}\text { Contact, asymmetric, impingement, } \\
\text { cutting }\end{array}$ \\
\hline Klingenstein et al (2012) $)^{38}$ & $4,7,8$ & Asymmetric, cutting \\
\hline Levy et al $(2017)^{39}$ & $3,4,7$ & Endurance \\
\hline Malagelada et al $(2015)^{25}$ & $1-4$ & Endurance, cutting, contact \\
\hline Malviya et al $(2013)^{26}$ & $1-8$ & $\begin{array}{l}\text { Cutting, impingement, contact, } \\
\text { asymmetric, flexibility, endurance }\end{array}$ \\
\hline McDonald et al (2014) $)^{32}$ & 8 & Impingement \\
\hline Menge et al $(2016)^{40}$ & 8 & Impingement \\
\hline Naal et al $(2011)^{41}$ & 7,8 & Impingement, asymmetric, cutting \\
\hline Naal et al $(2014)^{42}$ & $0-8$ & $\begin{array}{l}\text { Cutting, flexibility, asymmetric, } \\
\text { endurance, impingement }\end{array}$ \\
\hline Newman et al $(2016)^{43}$ & 6 & Asymmetric \\
\hline Nho et al $(2011)^{44}$ & $5-8$ & $\begin{array}{l}\text { Cutting, contact, impingement, } \\
\text { asymmetric, endurance }\end{array}$ \\
\hline Novais et al $(2016)^{45}$ & 4 & $\begin{array}{l}\text { Cutting, contact, flexibility, asymmetric } \\
\text { endurance }\end{array}$ \\
\hline Perets et al $(2017)^{46}$ & $5-8$ & $\begin{array}{l}\text { Cutting, flexibility, contact, asymmetric } \\
\text { endurance }\end{array}$ \\
\hline Philippon et al $(2007)^{47}$ & $5-8$ & $\begin{array}{l}\text { Cutting, flexibility, contact, } \\
\text { impingement, asymmetric }\end{array}$ \\
\hline Philippon et al (2008) ${ }^{29}$ & $2-4$ & $\begin{array}{l}\text { Cutting, flexibility, } \\
\text { impingement, asymmetric }\end{array}$ \\
\hline Philippon et al $(2010)^{48}$ & 8 & Impingement \\
\hline Polesello et al $(2012)^{50}$ & Not reported & Not reported \\
\hline Polesello et al (2014) ${ }^{49}$ & Not reported & Not reported \\
\hline Ribas et al $(2007)^{51}$ & $1-4$ & Cutting, flexibility, contact, endurance \\
\hline Sansone et al $(2015)^{27}$ & 7,8 & $\begin{array}{l}\text { Cutting, flexibility, contact, } \\
\text { impingement, asymmetric, endurance }\end{array}$ \\
\hline Shibata et al $(2017)^{14}$ & $5-8$ & $\begin{array}{l}\text { Cutting, flexibility, contact, } \\
\text { impingement, asymmetric, endurance }\end{array}$ \\
\hline Singh and O'Donnell $(2010)^{52}$ & 8 & Contact \\
\hline Tjong et al $(2016)^{53}$ & 7 & Endurance \\
\hline Tran et al $(2013)^{54}$ & $1-4$ & $\begin{array}{l}\text { Cutting, flexibility, contact, } \\
\text { impingement, asymmetric, endurance }\end{array}$ \\
\hline Weber et al (2016) $)^{31}$ & $1-4$ & Not reported \\
\hline Zingg et al $(2013)^{28}$ & Not reported & Not reported \\
\hline
\end{tabular}

HSAS, Hip Sports Activity Scale.

eight (23\%) were of low quality. ${ }^{2433} 343637394952$ There were no high-quality studies. Only three studies ${ }^{30} 3244$ reported blinding of assessors with respect to outcome measurement (item 5).

\section{Demographic characteristics of included studies}

There were 1634 participants/1828 hips included. There were 499 women and 1135 men in included studies. The mean age of included athletes was $27.1 \pm 7.8$ years. 


\section{Return to Sport at Preinjury Level, Athlete Level}

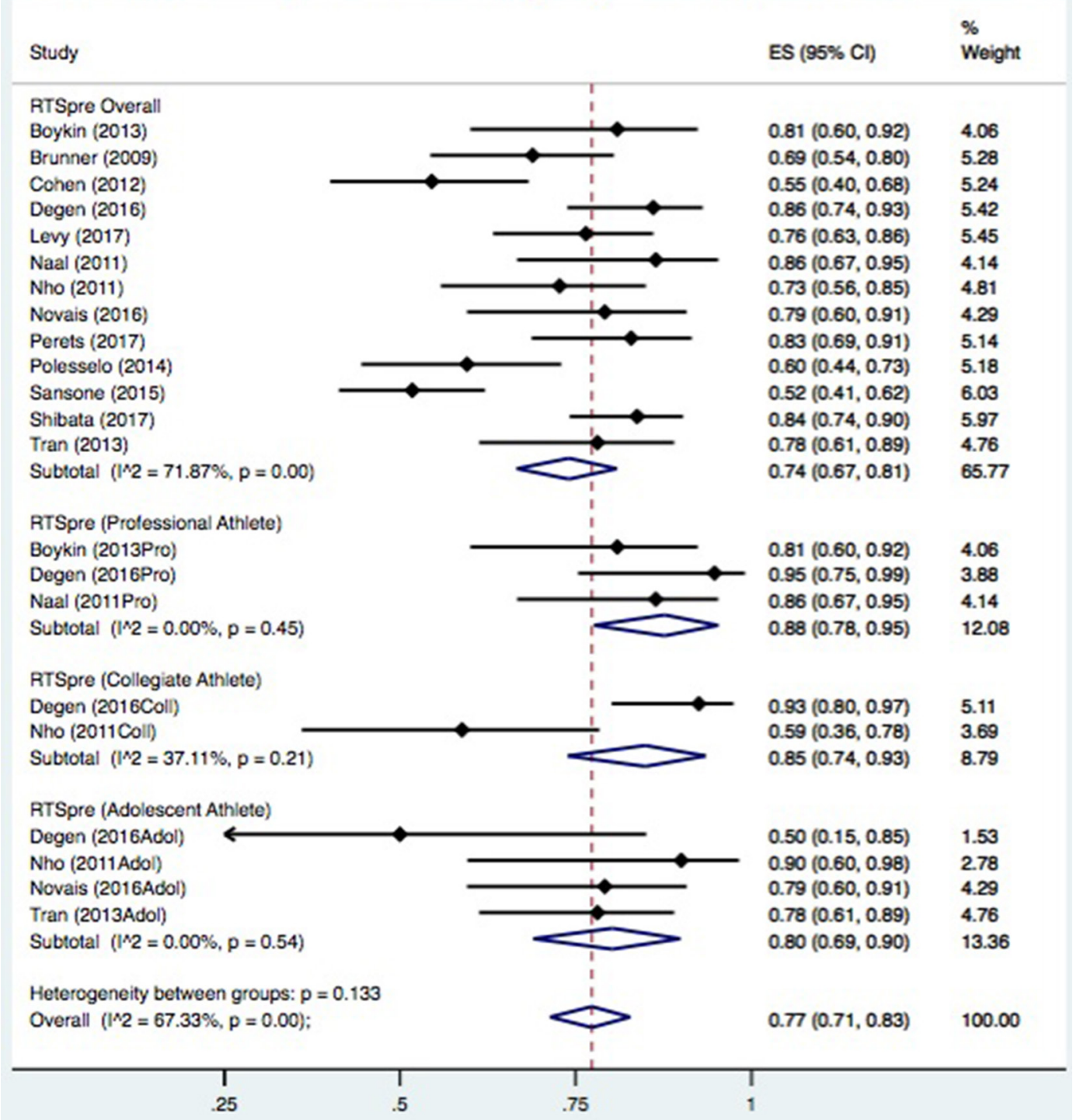

Figure 2 Return to sport at previous level, overall and by athlete competition level. Pooled rates of return to sport at preinjury level (RTS ${ }_{\mathrm{PRE}}$ ) (overall (74\%), professional athletes (88\%), collegiate athletes (85\%) and adolescent athletes (80\%)). ES, effectsize, which is actually a proportion. Dashed line represents the relationship between the overall pooled estimate and the individual study and category pooled estimates.

\section{Type of sports included}

The sports with the greatest number of athletes studied were ice hockey $(n=201)$, football $(n=161)$, baseball $(n=138)$, running/ jogging $(n=116)$, American football $(n=89)$, Australian football $(n=67)$, basketball $(n=46)$ and golf $(n=45)$. Table 2 lists the modified English version ${ }^{14}$ (level 1: recreational through level 8: competitive sports, elite level) of the Hip Sports Activity Scale ${ }^{16}$ and the modified version ${ }^{14}$ of the sports categories ${ }^{15}$ (six distinct categories based on the mechanical loads placed on the hip by the sporting activity) for each respective study. There were 51 other sports in which at least one athlete received surgery for FAI syndrome.

The sports categories represented in the included studies were $^{1415}$ cutting sports ( $n=23$ studies, 263 athletes), impingement-related sports ( $\mathrm{n}=20$ studies, 222 athletes), contact sports ( $n=19$ studies, 166 athletes), asymmetric/overhead sports $(n=21$ studies, 260 athletes), flexibility-related sports ( $\mathrm{n}=15$ studies, 74 athletes) and endurance-related sports ( $n=17$ studies, 222 athletes). Several studies included athletes in more than one category (table 1).

\section{Surgical procedure}

Arthroscopy was used in 28 studies, ${ }^{1421} 2224262729-40434446-5052-54$ open surgical procedure in 3 studies, ${ }^{414245}$ mini-open in 3 studies, ${ }^{2325} 51$ and a combination of arthroscopy and open in 1 study $^{28}$ (online supplementary appendix IV). All but two studies ${ }^{51} 53$ reported on concomitant procedures (multiple procedures performed on the same athlete). On average, each study reported five different surgical procedures on the hip. The specific procedures used were clear in 31 (89\%) studies, ${ }^{14}$ 21-25 27-29 31-41 43 45-48 505254 with femoroplasty reported as the most common procedure.

Complications were addressed or reported on in only 18 (51\%) studies. ${ }^{14} 21-232527-2931333536394546515354$ The overall mean complication rate was $6.25 \% \pm 12.8 \%$ for the 18 studies 
Table 3 Differences among RTS and RTSPRE (athlete competition level)

\begin{tabular}{|c|c|c|c|}
\hline & Rate $(95 \% \mathrm{Cl})$ & Participants (n) & Difference ( $p$ values) \\
\hline \multicolumn{4}{|l|}{ Return to sport } \\
\hline Professional vs collegiate & 97 (94 to 99$)$ vs 89 (73 to 99$)$ & 419 vs 132 & $\begin{array}{l}\text { Professional athletes return to sport at a higher rate than } \\
\text { collegiate athletes ( } 8 \%(2.8 \% \text { to } 14.8 \%), p=0.0002)\end{array}$ \\
\hline Collegiate vs adolescent & 89 (73 to 99$)$ vs 95 ( 84 to 100$)$ & 132 vs 123 & No difference \\
\hline \multicolumn{4}{|l|}{$\mathrm{RTS}_{\mathrm{PRE}}$} \\
\hline Collegiate vs adolescent & 85 (74 to 93 ) vs 80 (69 to 90$)$ & 57 vs 70 & No difference \\
\hline \multicolumn{4}{|c|}{ Return to sport vs return to preinjury level of sport } \\
\hline Professional RTS vs RTS ${ }_{\text {PRE }}$ & 97 (94 to 99$)$ vs 88 (78 to 95$)$ & 419 vs 62 & $\begin{array}{l}\text { Professional athletes return to sport at a } 9 \%(1.8 \% \text { to } 19.8 \%) \\
\text { higher rate than } \mathrm{RTS}_{\mathrm{PRE}}(\mathrm{p}=0.0009) \text {. }\end{array}$ \\
\hline Collegiate RTS vs RTS $S_{\text {PRE }}$ & 89 (73 to 99$)$ vs 85 (74 to 93$)$ & 132 vs 57 & $\begin{array}{l}\text { Collegiate athletes return to sport at a } 4 \%(-6.4 \% \text { to } 16.9 \%) \\
\text { higher rate than } \mathrm{RTS} S_{\text {PRE }}(p=0.44) \text {. }\end{array}$ \\
\hline \multicolumn{4}{|c|}{ Rate of RTS was $17 \%(16.8 \%$ to $17.2 \%)$ higher than the RTS ${ }_{\text {PRE }}$ rate based on athlete level $(p<0.0001)$. } \\
\hline
\end{tabular}

RTS, return to sport; $\mathrm{RTS}_{\mathrm{PRE}^{\prime}}$ return to preinjury level of sport competition.

reporting complications. Eight (23\%) studies reported no complications. ${ }^{14293945465354}$

Failures, as defined by total hip replacement or revision hip arthroscopy, were addressed or reported in $25(77 \%)$ studies. $^{21-25} 27-29313335-3739414345-49515254$ The overall mean failure rate was $7.5 \% \pm 7.3 \%$ for the 27 studies reporting failures. Six (17\%) studies reported no failures. ${ }^{29} 3135395254$ In those studies that reported failures, revision surgery was performed on $2.3 \%$ of hips included, and total hip arthroplasty was performed on $1 \%$ of hips included.

Nine (26\%) studies reported on the time from symptom onset/injury to surgery. ${ }^{142729313536404148}$ The mean time was $15.9 \pm 7.5$ months, with a mean range of $2.5 \pm 2$ to $68.4 \pm 33.9$ months.

\section{RTS rates}

All pooled RTS and $\mathrm{RTS}_{\mathrm{PRE}}$ rates were based on limited evidence, except in the case of adolescent athlete RTS $_{\mathrm{PRE}}$ (moderate evidence). ${ }^{12}$ Based on all 35 studies, the pooled rate for RTS (at any level) following surgery for FAI syndrome was 91\% (95\% CI $88 \%$ to $\left.94 \% ; \mathrm{I}^{2}=75 \% ; \mathrm{n}=1634\right)$. Based on 13 studies, ${ }^{142324273035394144-465054}$ the pooled rate of $\mathrm{RTS}_{\mathrm{PRE}}$ returning to the same level of competition as before the surgerywas $74 \%$ (95\% CI $67 \%$ to $81 \% ; \mathrm{I}^{2}=71.9 \% ; \mathrm{n}=570$ ) (figure 2).

\section{Athlete level}

The RTS and RTS $_{\mathrm{PRE}}$ rates varied by the athlete's level of competition. Details on these differences, and their significance, are provided in table 3, figures 2 and 3, and online supplementary appendix $\mathrm{V}$.

\section{Surgical technique}

Among athletes who underwent an arthroscopic procedure, there was a $17 \%(12.8 \%-21.4 \%)$ difference between rates of RTS and RTS $_{\text {PRE }}(\mathrm{p}<0.0001)$. Athletes who underwent an open surgical procedure had a $6 \%(-4.9 \%$ to $20.6 \%)$ difference between rates of RTS and $\operatorname{RTS}_{\text {PRE }}(p=0.27)$. The mini-open surgical procedure only had one study qualified for $\mathrm{RTS}_{\mathrm{PRE}}$, so we did not make the RTS to RTS $_{\text {PRE }}$ comparison. No differences

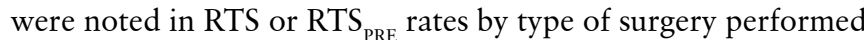
in our meta-analysis figures 4 and 5 .

\section{Time taken to return to sport}

Thirteen (37\%) studies reported on the time between surgery and RTS. ${ }^{14} 24-26313436373943-4551$ The mean time to RTS was $7 \pm 2.6$ months (mean range $3.1 \pm 1.5$ to $14.5 \pm 7.7$ months).

\section{Criteria for readiness to return to sport}

None of the included 35 studies reported the criteria used to determine readiness to return to sport other than time that had elapsed postsurgery. The international consensus statement on return to play $^{6}$ suggests criteria should be reported.

\section{Reporting players' postsurgery athletic performance}

Five (14\%) studies 2632353943 reported on preinjury and postsurgery athletic performance in football (soccer), ${ }^{35}$ running, ${ }^{39}$ ice hockey, ${ }^{32}$ golf ${ }^{43}$ and multiple sports. ${ }^{26}$ Performance measurements included the average number of starts in professional football players, ${ }^{35}$ decreased running mileage in non-professional athletes $(p=0.013),{ }^{39}$ decreased performance data $(p=0.024)$ in professional hockey players $^{32}$ and reaching the greens in regulation for professional golfers (no difference between presurgery and postsurgery; $p=0.227) .{ }^{43} \mathrm{~A}$ study of 80 athletes in various sports with a mean follow-up of 17 months found an improvement in the time/week in sport competition from a mean of 2.5 hours before surgery to 5.2 hours 6 months after surgery $(p=0.02)$ and 7.9 hours 1 year after surgery $(p<0.001) .{ }^{26}$ Actual performance in sport competition was not reported.

\section{Postsurgical follow-up duration and participant retention} All but four studies 32374043 reported on length of postsurgical follow-up. The mean postsurgery follow-up was $28.1 \pm 15.5$ months in $89 \%$ of studies that reported this variable. Follow-up ranged from 12 months $^{2528}$ to 73.2 months. $^{49}$ 


\section{Return to Sport, Athlete Level}

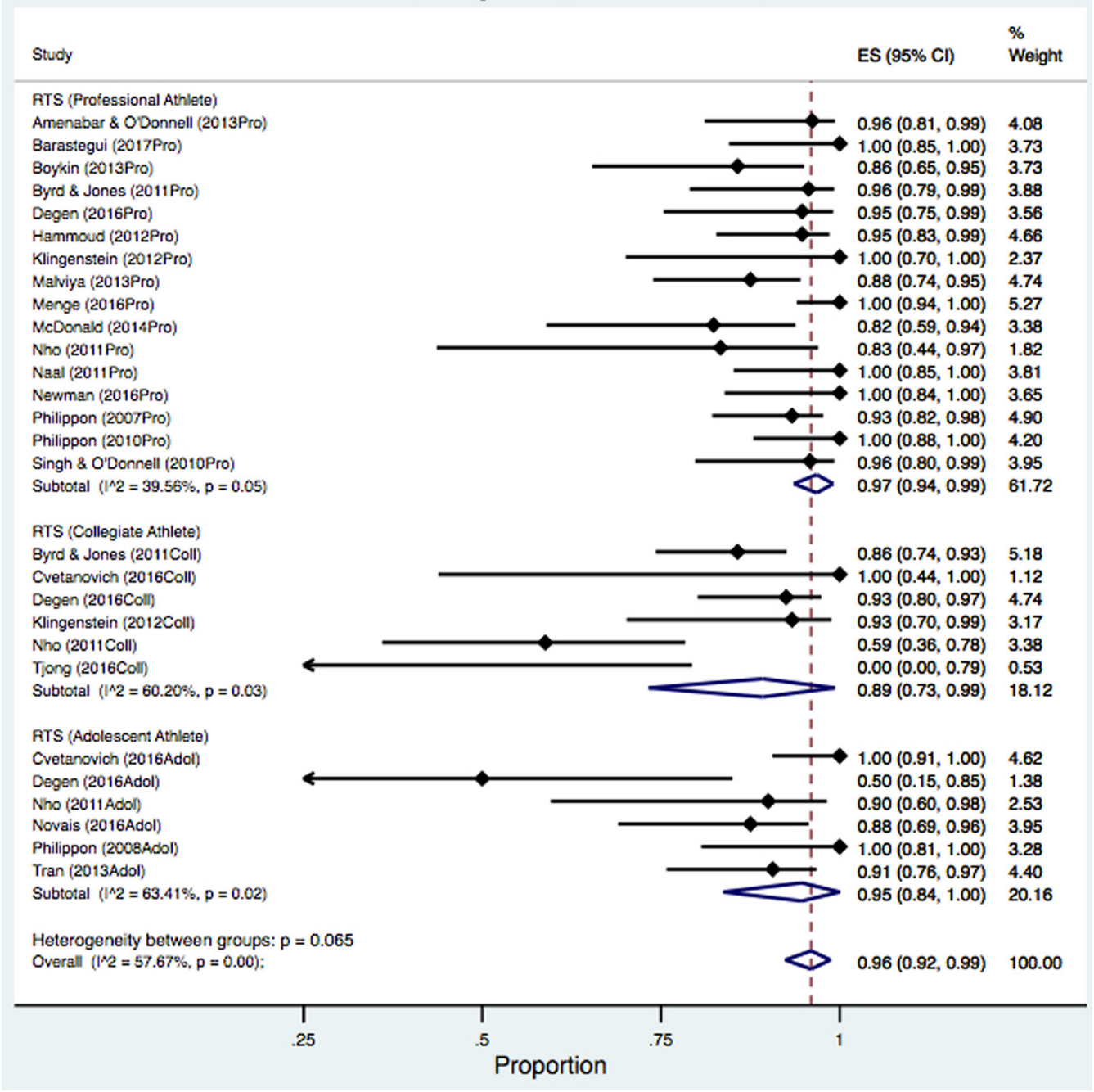

Figure 3 Return to sport (RTS) by athlete competition level. Pooled rates of RTS (professional athlete (97\%), collegiate athlete (89\%), adolescent athlete $(95 \%)$ ). ES (effect size)=return to sport rate with $95 \% \mathrm{Cl}$. Dashed line represents the relationship between the overall pooled estimate and the individual study and category pooled estimates.

\section{Career longevity}

Career longevity was reported in seven (20\%) studies. ${ }^{32-3440434748}$

\section{Patient-reported outcome measures}

Pooled mean differences in PROMs are presented in figure 6. The Modified Harris Hip Score was the most frequently used PROM (n=14 studies). ${ }^{1429313334363944-4648-5054}$ Satisfaction was also measured (various measures) in 13 studies. ${ }^{27} 29-3135414248-5053-55$ All PROMs demonstrated improvement from before to after surgery.

\section{DISCUSSION}

Nine out of 10 athletes returned to sport after surgery for FAI syndrome. This can be considered one level of 'success' of the surgical procedure. We also found that between 2 and 3 of 10 athletes failed to return to their preinjury level of competition after surgery. This is data that surgeons should discuss with athletes as part of a preooperative shared decision making. Returning to competitive sport at a high level is often a factor that makes athletes consider surgery, so capacity to return to play at a previous competition level warrants specific discussion between the surgeon and the athlete. Going beyond merely the 'level of competition' to the 'capacity for best ever performance' is another important consideration for patients, yet only $14 \%$ of studies compared sporting performance before and after players had undergone surgery for FAI syndrome.

Across all levels of athletic level of competition, athletes returned to sport at an average of 7 months after surgery $(37 \%$ of studies reported this outcome). ${ }^{14} \quad 24-26313436 \quad 373943-45 \quad 51$ Professional athletes also returned to sport at an average of 7 months. ${ }^{343743}$ While our results should be interpreted cautiously given the small number of studies, it is likely that professional athletes do not consistently return to sport as rapidly as expected, ${ }^{56}$ despite access to more consistent and frequent postsurgical care than non-professional athletes. Professional athletes may return to sport in higher rates, but not necessarily to the preinjury level of competition. Collegiate and adolescent athletes are less likely to experience the level of significant socioeconomic pressure to RTS that professional athletes do. ${ }^{4144} 47$ The non-professional athlete does not rely on RTS/RTS ${ }_{\mathrm{PRE}}$ financially, which may mean there is a lesser financial motivation to return to play compared with a professional athlete after surgery. 


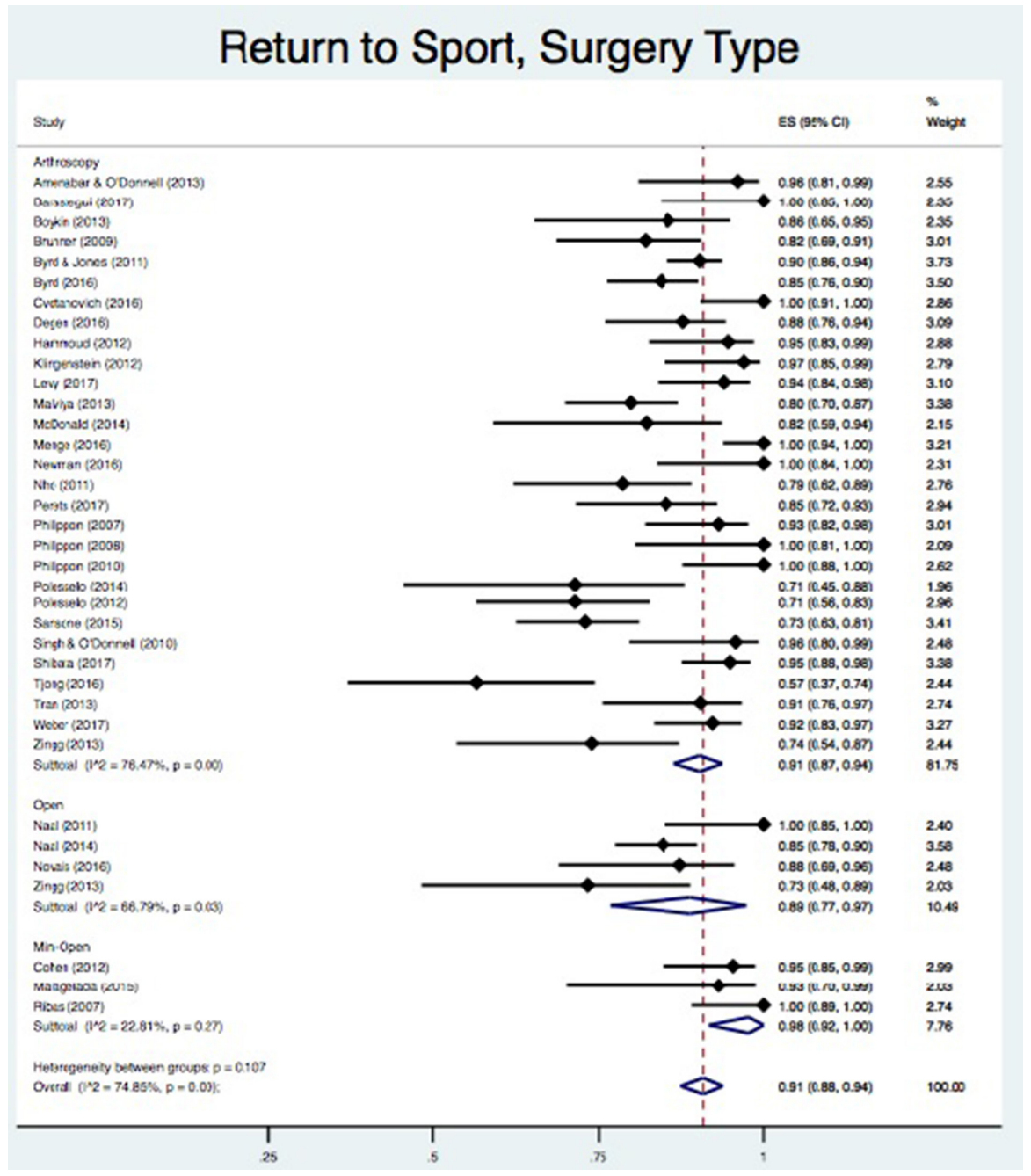

Figure 4 Return to sport (RTS) by surgery type/technique. Pooled rate of RTS (arthroscopy (91\%), open (89\%), mini-open (98\%)). ES (effect size) $=$ return to sport rate with $95 \% \mathrm{Cl}$, which is actually a proportion. Dashed line represents the relationship between the overall pooled estimate and the individual study and category pooled estimates.

It is important to discuss the fact that a proportion of players are restricted in their ability to participate in sport postsurgery. ${ }^{57}$ Athletes typically choose surgery for pain relief and $\mathrm{RTS}_{\mathrm{PRE}}{ }^{5}$ Our results suggest that current studies are at moderate to high risk of bias and inadequately report surgical outcomes. It is of concern that no studies reported on criteria used to determine RTS beyond postsurgical time. This suggests that there may be inconsistency in when players are allowed to return to sport. This has clinical implications as well as implications for consistency of reporting outcome research.

We found that PROMs improved; patients generally reported fewer symptoms and felt satisfied with the procedure. A limited number of studies reported on the following: surgical complications (51\% of included studies reporting on complications), surgical failures (77\% reported), career longevity postsurgery (20\% reported), time frame from surgery to RTS (34\% reported), actual athletic performance postsurgery (14\% reported), and criteria to determine athlete readiness to return to sport $(0 \%$ reported).

Given that one in four athletes did not return to the preinjury level of sport competition level (as highlighted above), the high level of reported satisfaction and significant improvement in presurgical to postsurgical PROMs suggests that athletes' decision making may be based on limited information. Players may be anticipating RTS/RTS ${ }_{\mathrm{PRE}}$ success, ${ }^{58}$ and they may overestimate their satisfaction in relation to sport performance postsurgery. ${ }^{304248}$

\section{Comparison with previous reviews}

Two previous reviews ${ }^{34}$ have examined RTS in athletes with FAI syndrome. Our review used strict criteria on study inclusion and $\mathrm{RTS}_{\mathrm{PRE}}$ definition. Additionally, our review is more comprehensive, including the most recent studies, as well as reporting on

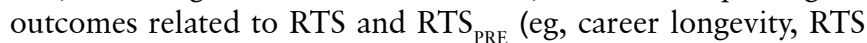

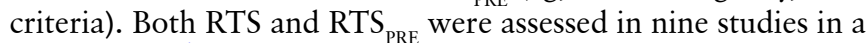
2012 review. ${ }^{4}$ They reported an RTS rate of $92 \%$ and an $\mathrm{RTS}_{\mathrm{PRE}}$ rate of $88 \%$. Our RTS rate was similar (91\%), but our RTS PRE rate was lower (74\%). Our review included an overall larger number of studies and more strict criteria for study inclusion,

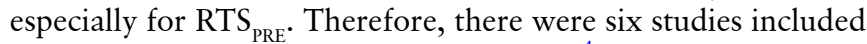
in the meta-analysis in this previous review ${ }^{4}$ that either were not included in our review due to small study size $e^{59}$ or not included in the calculation of RTS $_{\text {PRE }}$ due to lack of clarity for actual $\mathrm{RTS}_{\mathrm{PRE}}{ }^{21} 29474852$ Including these studies in the previous review may have overestimated the RTS $_{\text {PRE }}$ rate.

A review of 18 level 4 studies assessed both RTS and RTS PRE $_{\text {, }}$ with findings of $87 \%$ RTS and $82 \% \mathrm{RTS}_{\mathrm{PRE}}{ }^{3}$ Similar to our 


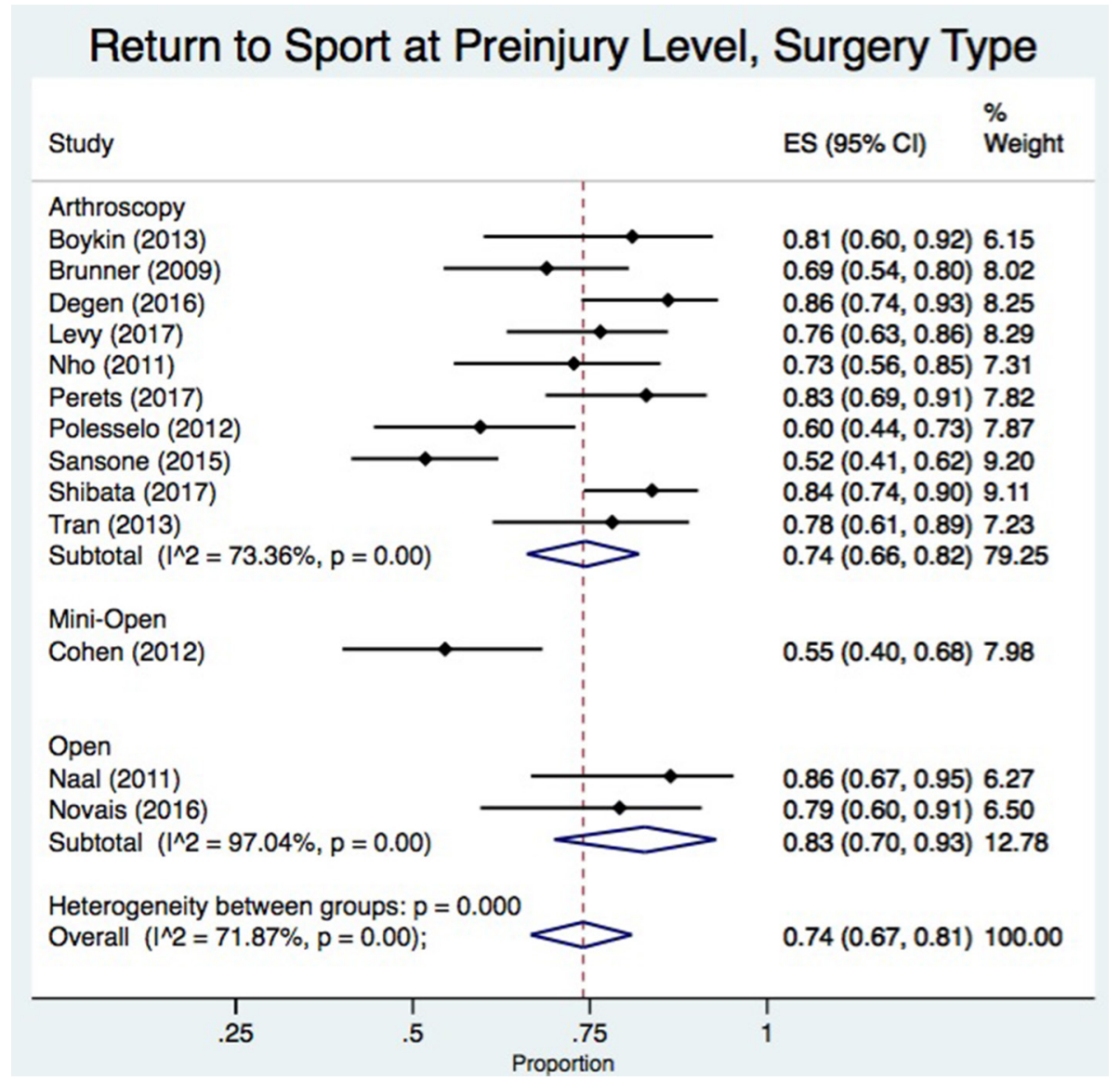

Figure 5 Return to sport at previous level by surgery type/technique. Pooled return to sport at preinjury level (arthroscopy (74\%), open (83\%), miniopen (single study: $55 \%$ )). ES (effect size)=return to sport rate with $95 \% \mathrm{Cl}$, which is actually a proportion. Dashed line represents the relationship between the overall pooled estimate and the individual study and category pooled estimates.

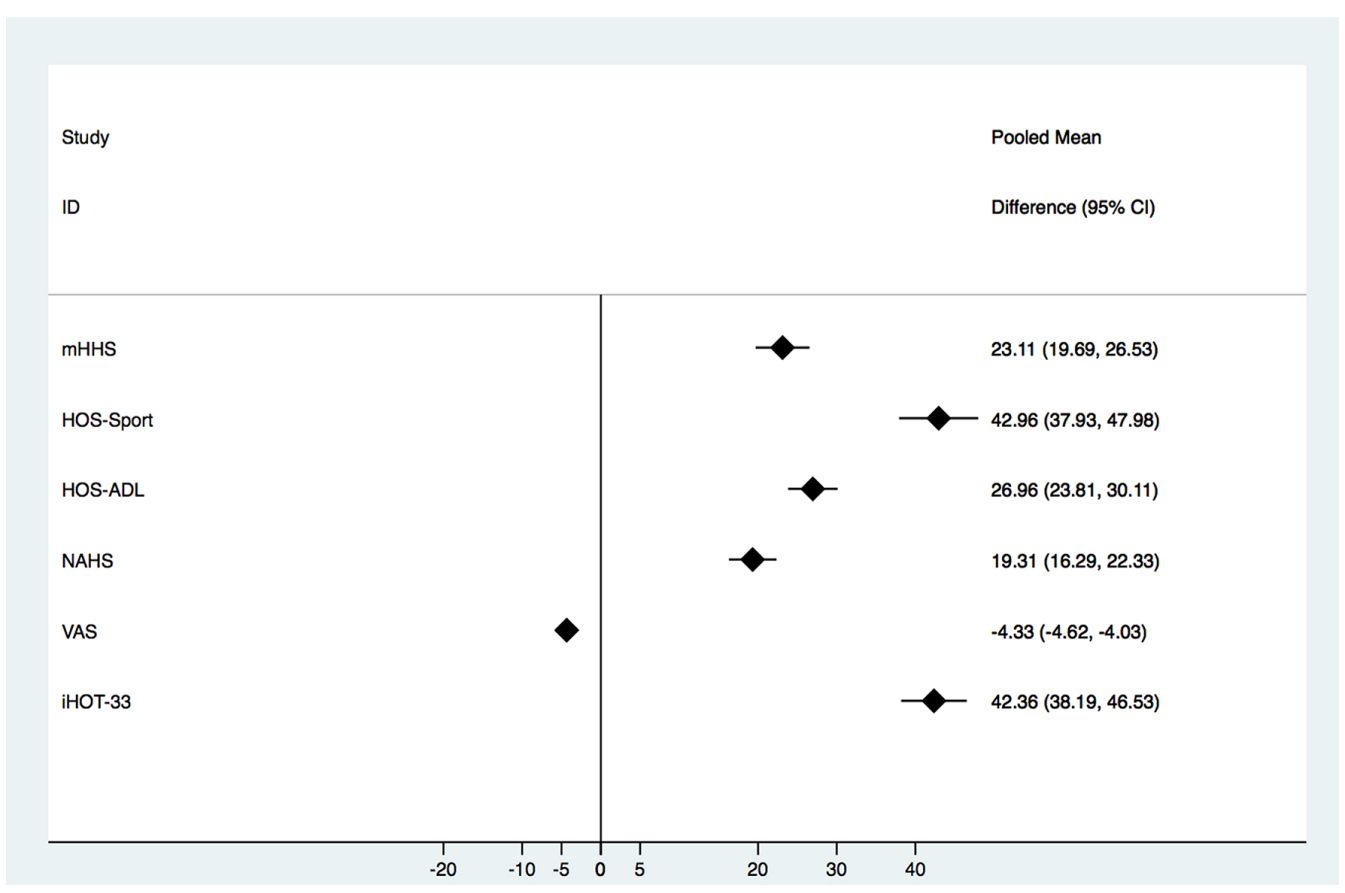

Figure 6 Pooled mean differences $( \pm S D)$ for most commonly used patient-reported outcomes. mHHS, modified Harris Hip Score; HOS, Hip Outcome Score; HOS-ADL, Hip Outcome Score, Activities of Daily Living Subscale; NAHS, Nonarthritic Hip Score; VAS, Visual Analog Scale; iHOT-33, 33-item International Hip Outcome Tool. 
review, they also compared athlete level. This review did not

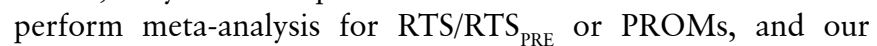
review included more recent studies. Our review omitted studies with fewer than 10 patients. Additionally, our review synthesises twice as many studies as did previous reviews, as well as the most recent outcome measures (eg, PROMs, career longevity, RTS criteria, postsurgical follow-up duration, surgical complications and failures, as well as athletic performance postsurgery), many variables not previously reported. These outcome measures provide context of success/failure of the surgery, providing the surgeon and the patient with information that may help treatment decision making.

Finally, our rating of published studies' methodological quality was lower than that reported in previous reviews. We used MINORS ${ }^{8}$ as well as recent suggestions of quality score stratification. ${ }^{9}{ }^{10}$ Our review describes the most current, stringently defined RTS rates for patients with FAI syndrome.

\section{Strengths and limitations}

Our review is the most comprehensive evaluation of RTS and RTS $_{\text {PRE }}$ following surgical treatment for FAI syndrome. We synthesised data from 1634 athletes of various levels and we reported pooled analysis of levels of competitive participation and the effect of various surgical techniques on outcomes.

A limitation is that to be included, studies had to report quantifiable numbers of athletes who returned to sport. Therefore, studies that evaluated RTS with using only PROMs or activity rating scales (eg, Tegner Activity Scale) were not included. The findings of this review should be interpreted with some caution due to the low quality and limited reporting of included studies. Well-designed, prospective cohort studies are necessary to more completely determine RTS and RTS ${ }_{\mathrm{PRE}}$ rates. Randomised controlled trials with patients stratified by severity of symptoms would be required to directly compare RTS and RTS ${ }_{\text {PRE }}$ rates across different surgical techniques. We did not use duplicate data extraction, although a second author independently verified

\section{What is already known on this topic?}

- Previous reviews suggest most athletes return to sport after hip arthroscopy.

\section{What are the findings?}

- Only $74 \%$ of athletes returned to sport at the previous level of competition; only $37 \%$ of studies clearly distinguished return to sport (RTS) (at any level) from RTS at the previous level of competition.

- Athletic performance (eg, personal data comparison) is not well reported after surgery for femoroacetabular impingement (FAl) syndrome. Whether FAl syndrome is career-limiting (no further improvement post surgery) is unknown from present studies.

- The field will be advanced by researchers reporting (1) criteria used for determining RTS $(0 \%$ of included studies reported these), (2) time from surgery to RTS (34\% of studies reported this), (3) career longevity post-surgery ( $20 \%$ of studies reported this), (4) presurgery to postsurgery athletic performance $(14 \%$ of studies reported this, (5) surgical complications ( $51 \%$ of studies reported this), and (6) surgical failures ( $77 \%$ of studies reported this). the data extraction. Note that we only included studies that were published in the English language.

\section{CONCLUSION}

One in four athletes did not return to the preinjury level of competitive sports participation after surgical treatment for FAI syndrome. Athletic performance (eg, personal data comparison) is not well reported after surgery for FAI syndrome.

Acknowledgements The authors would like to thank Leila Ledbetter, MLIS, for assisting with the literature search for this study.

Contributors MPR contributed the idea of the manuscript, initial registration of review, initial search, review of data, initial drafting and editing of the manuscript. SP, JS and SH contributed to initial search, data extraction and editing of the manuscript. APG independently performed statistical analysis, as well as review and editing of the manuscript after analysis. RCM contributed to review and editing of the manuscript.

Funding This research received no specific grant from any funding agency in the public, commercial or not-for-profit sectors.

Competing interests RCM: consultant for Stryker and KNG Health Consulting; research support from Zimmer and AOSSM; and board position on North Carolina Orthopaedic Association.

Patient consent Not required.

Provenance and peer review Not commissioned; externally peer reviewed. Data sharing statement Data available upon request.

(c) Article author(s) (or their employer(s) unless otherwise stated in the text of the article) 2018. All rights reserved. No commercial use is permitted unless otherwise expressly granted.

\section{REFERENCES}

1 Griffin DR, Dickenson EJ, O'Donnell J, et al. The Warwick agreement on femoroacetabular impingement syndrome (FAI syndrome): an international consensus statement. Br J Sports Med 2016;50:1169-76.

2 Kemp JL, Makdissi M, Schache AG, et al. Hip chondropathy at arthroscopy: prevalence and relationship to labral pathology, femoroacetabular impingement and patientreported outcomes. Br J Sports Med 2014;48:1102-7.

3 Casartelli NC, Leunig M, Maffiuletti NA, et al. Return to sport after hip surgery for femoroacetabular impingement: a systematic review. Br J Sports Med 2015;49:819-24

4 Alradwan H, Philippon MJ, Farrokhyar F, et al. Return to preinjury activity levels after surgical management of femoroacetabular impingement in athletes. Arthroscopy 2012;28:1567-76

5 Peters S, Laing A, Emerson C, et al. Surgical criteria for femoroacetabular impingement syndrome: a scoping review. Br J Sports Med 2017;51:1605-10.

6 Ardern CL, Glasgow P, Schneiders A, et al. 2016 Consensus statement on return to sport from the First World Congress in Sports Physical Therapy, Bern. Br I Sports Med 2016;50:853-64

7 Doust JA, Pietrzak E, Sanders S, et al. Identifying studies for systematic reviews of diagnostic tests was difficult due to the poor sensitivity and precision of methodologic filters and the lack of information in the abstract. J Clin Epidemiol 2005;58:444-9.

8 Slim K, Nini E, Forestier D, et al. Methodological index for non-randomized studies (minors): development and validation of a new instrument. ANZ J Surg 2003;73:712-6.

9 Braga LH, Mijovic H, Farrokhyar F, et al. Antibiotic prophylaxis for urinary tract infections in antenatal hydronephrosis. Pediatrics 2013;131:e251-e261.

10 Yeung M, Kowalczuk M, Simunovic N, et al. Hip arthroscopy in the setting of hip dysplasia: A systematic review. Bone Joint Res 2016;5:225-31.

11 Center for evidence based medicine. Oxford centre for evidence-based medicine, levels of evidence. Oxford: University of Oxford, 2009. (accessed 1 Aug 2015).

12 van Tulder M, Furlan A, Bombardier C, et al. Updated method guidelines for systematic reviews in the cochrane collaboration back review group. Spine 2003;28:1290-9.

13 Rathleff MS, Rathleff CR, Crossley KM, et al. Is hip strength a risk factor for patellofemoral pain? A systematic review and meta-analysis. Br J Sports Med 2014;48:1088

14 Shibata KR, Matsuda S, Safran MR. Arthroscopic hip surgery in the elite athlete: comparison of female and male competitive athletes. Am J Sports Med 2017:45:1730-9

15 Nawabi DH, Bedi A, Tibor LM, et al. The demographic characteristics of high-level and recreational athletes undergoing hip arthroscopy for femoroacetabular impingement: a sports-specific analysis. Arthroscopy 2014;30:398-405.

16 Naal FD, Miozzari HH, Kelly BT, et al. The Hip Sports Activity Scale (HSAS) for patients with femoroacetabular impingement. Hip Int 2013;23:204-11. 
17 Akobeng AK. Understanding systematic reviews and meta-analysis. Arch Dis Child 2005;90:845-8

18 DerSimonian R, Laird N. Meta-analysis in clinical trials. Control Clin Trials 1986:7:177-88

19 Freeman MF, Tukey JW. Transformations related to the angular and the square root. The Annals of Mathematical Statistics 1950;21:607-11.

20 Higgins JP, Thompson SG, Deeks JJ, et al. Measuring inconsistency in meta-analyses. BMJ 2003:327:557-60.

21 Byrd JWT, Jones KS. Arthroscopic management of femoroacetabular impingement in athletes. Am J Sports Med 2011;39:7-13.

22 Byrd JW, Jones KS, Gwathmey FW. Femoroacetabular Impingement in adolescent athletes: outcomes of arthroscopic management. Am J Sports Med 2016;44:2106-11.

23 Cohen SB, Huang R, Ciccotti MG, et al. Treatment of femoroacetabular impingement in athletes using a mini-direct anterior approach. Am J Sports Med 2012:40:1620-7.

24 Degen RM, Fields KG, Wentzel CS, et al. Return-to-play rates following arthroscopic treatment of femoroacetabular impingement in competitive baseball players. Phys Sportsmed 2016;44:385-90.

25 Malagelada F, Del Carmen VA, Barke SJ, et al. The anterior mini-open approach for femeroacetabular impingement: Gait and functional assessment at one year postsurgery. Ann Phys Rehabil Med 2015;58:60-5.

26 Malviya A, Paliobeis CP, Villar RN. Do professional athletes perform better than recreational athletes after arthroscopy for femoroacetabular impingement? Clin Orthop Relat Res 2013:471:2477-83.

27 Sansone M, Ahldén M, Jonasson P, et al. Good Results After Hip Arthroscopy for Femoroacetabular Impingement in Top-Level Athletes. Orthop J Sports Med 2015;3:23.

28 Zingg PO, Ulbrich EJ, Buehler TC, et al. Surgical hip dislocation versus hip arthroscopy for femoroacetabular impingement: clinical and morphological short-term results. Arch Orthop Trauma Surg 2013;133:69-79.

29 Philippon MJ, Yen YM, Briggs KK, et al. Early outcomes after hip arthroscopy for femoroacetabular impingement in the athletic adolescent patient: a preliminary report. J Pediatr Orthop 2008;28:705-10.

30 Brunner A, Horisberger M, Herzog RF. Sports and recreation activity of patients with femoroacetabular impingement before and after arthroscopic osteoplasty. Am J Sports Med 2009;37:917-22.

31 Weber AE, Kuhns BD, Cvetanovich GL, et al. Amateur and recreational athletes return to sport at a high rate following hip arthroscopy for femoroacetabular impingement. Arthroscopy 2016 (accessed 5 Jan 2017).

32 McDonald JE, Herzog MM, Philippon MJ. Performance outcomes in professional hockey players following arthroscopic treatment of FAl and microfracture of the hip. Knee Surg Sports Traumatol Arthrosc 2014;22:915-9.

33 Amenabar T, O'Donnell J. Return to sport in Australian football league footballers after hip arthroscopy and midterm outcome. Arthroscopy 2013;29:1188-94.

34 Barastegui D, Seijas R, Alvarez-Diaz P, et al. Assessing long-term return to play after hip arthroscopy in football players evaluating risk factors for good prognosis. Knee Surg Sports Traumatol Arthrosc 2017 Epub ahead of print 19 May 2017.

35 Boykin RE, Patterson D, Briggs KK, et al. Results of arthroscopic labral reconstruction of the hip in elite athletes. Am J Sports Med 2013;41:2296-301.

36 Cvetanovich GL, Weber AE, Kuhns BD, et al. Clinically meaningful improvements after hip arthroscopy for femoroacetabular impingement in adolescent and young adult patients regardless of gender. J Pediatr Orthop 2016:1[Epub ahead of print 31 Jul 2016].

37 Hammoud S, Bedi A, Magennis E, et al. High incidence of athletic pubalgia symptoms in professional athletes with symptomatic femoroacetabular impingement. Arthroscopy 2012;28:1388-95.
38 Klingenstein GG, Martin R, Kivlan B, et al. Hip injuries in the overhead athlete. Clin Orthop Relat Res 2012:470:1579-85.

39 Levy DM, Kuhns BD, Frank RM, et al. High rate of return to running for athletes after hip arthroscopy for the treatment of femoroacetabular impingement and capsular plication. Am J Sports Med 2017;45:127-34

40 Menge TJ, Briggs KK, Philippon MJ. Predictors of length of career after hip arthroscopy for femoroacetabular impingement in professional hockey players. Am J Sports Med 2016:44:2286-91.

41 Naal FD, Miozzari HH, Wyss TF, et al. Surgical hip dislocation for the treatment of femoroacetabular impingement in high-level athletes. Am J Sports Med 2011:39:544-50.

42 Naal FD, Schär M, Miozzari HH, et al. Sports and activity levels after open surgical treatment of femoroacetabular impingement. Am J Sports Med 2014:42:1690-5.

43 Newman JT, Saroki AJ, Briggs KK, et al. Return to elite level of play and performance in professional golfers after arthroscopic hip surgery. Orthop J Sports Med 2016:4:23.

44 Nho SJ, Magennis EM, Singh CK, et al. Outcomes after the arthroscopic treatment of femoroacetabular impingement in a mixed group of high-level athletes. Am J Sports Med 2011;39(Suppl):14-19.

45 Novais EN, Mayo M, Kestel LA, et al. Return to play following open treatment of femoroacetabular impingement in adolescent athletes. J Am Acad Orthop Surg 2016;24:872-9.

46 Perets I, Hartigan DE, Chaharbakhshi EO, et al. Outcomes of hip arthroscopy in competitive athletes. Arthroscopy 2017 (accessed 17 May 2017).

47 Philippon M, Schenker M, Briggs K, et al. Femoroacetabular impingement in 45 professional athletes: associated pathologies and return to sport following arthroscopic decompression. Knee Surg Sports Traumatol Arthrosc 2007;15:908-14.

48 Philippon MJ, Weiss DR, Kuppersmith DA, et al. Arthroscopic labral repair and treatment of femoroacetabular impingement in professional hockey players. Am J Sports Med 2010;38:99-104.

49 Polesello GC, Lima FR, Guimaraes RP, et al. Arthroscopic treatment of femoroacetabular impingement: minimum five-year follow-up. Hip Int 2014;24:381-6.

50 Polesello GC, Cinagawa EH, Cruz PD, et al. Surgical treatment for femoroacetabular impingement in a group that performs squats. Rev Bras Ortop 2012;47:488-92.

51 Ribas M, Marín-Peña OR, Regenbrecht B, et al. Hip osteoplasty by an anterio minimally invasive approach for active patients with femoroacetabular impingement. Hip Int 2007;17:91-8.

52 Singh PJ, O'Donnell JM. The outcome of hip arthroscopy in Australian football league players: a review of 27 hips. Arthroscopy 2010:26:743-9.

53 Tjong VK, Cogan CJ, Riederman BD, et al. A Qualitative assessment of return to sport after hip arthroscopy for femoroacetabular impingement. Orthop J Sports Med 2016;4:23

54 Tran P, Pritchard M, O'Donnell J. Outcome of arthroscopic treatment for cam type femoroacetabular impingement in adolescents. ANZ J Surg 2013:83:382-6.

55 Sing DC, Feeley BT, Tay B, et al. Age-Related trends in hip arthroscopy: a large cross sectional analysis. Arthroscopy 2015:31:2307-13.

56 Helin K. Report: If Isaiah Thomas had hip surgery, he would be out 3-4 months. 2017.

57 Ardern CL, Webster KE, Taylor NF, et al. Return to sport following anterior cruciate ligament reconstruction surgery: a systematic review and meta-analysis of the state of play. Br J Sports Med 2011;45:596-606.

58 Haberstroh T. Isaiah Thomas' injury is potentially far more serious than you know: ESPN, Inc. 2017 http://www.espn.com/nba/story//id/20595342 (accessed 7 Sep 2017).

59 Bizzini M, Notzli HP, Maffiuletti NA. Femoroacetabular impingement in professional ice hockey players: a case series of 5 athletes after open surgical decompression of the hip. Am J Sports Med 2007;35:1955-9. 